\title{
Overexpression p21WAF1/CIP1 in suppressing retinal pigment epithelial cells and progression of proliferative vitreoretinopathy via inhibition CDK2 and cyclin E
}

Ying Wang ${ }^{1 \dagger}$, Zhigang Yuan ${ }^{1+}$, Caiyun You', Jindong Han ${ }^{1}$, Haiyan $\mathrm{Li}^{2}$, Zhuhong Zhang ${ }^{1}$ and Hua Yan ${ }^{{ }^{*}}$

\begin{abstract}
Background: P21 is one kind of cyclin-dependent kinase inhibitor that can prevent cells from going through the G1/S phase checkpoint and inhibit cell proliferation. Proliferative vitreoretinopathy (PVR) is a proliferative response in the eye. The aim of this study was to determine whether p21 Waf1/Cip1 (p21) suppresses the proliferation and migration of retinal pigment epithelial (RPE) cells in vitro and controls PVR development in vivo.

Methods: Cell cycle analyses and transwell assays were conducted to assess cell proliferation characteristics and the migration ability of RPE cells after transfection with p21. Western blot and reverse-transcription polymerase chain reaction technologies were used to detect the expression of p21, CDK ${ }_{2}$ and cyclinE in RPE cells and rabbit retinal tissues. The impact of increasing p21 expression on PVR development was conducted by implantation of an adenovirus vector containing rabbit $p 21$ (rAd-p21) in a PVR rabbit model. The prevalence of PVR and retinal detachment was determined by indirect ophthalmoscopy on days 3, 7, 14, and 21 after the injection of rAd-p21 into the vitreous. B scans and hematoxylin-eosin staining were employed to check rabbit retinas on day 21.
\end{abstract}

Results: Cell cycle analyses and transwell assays showed that p21 inhibited the proliferation and migration of RPE cells. Increased expression of p21 was detected in cultured RPE cells and rabbit retinas after transfection with the p21 gene, whereas levels of $\mathrm{CDK}_{2}$ and cyclinE were decreased. The increase in p21 expression effectively suppressed the development of PVR in a rabbit model.

Conclusions: The increase in p21 expression in RPE cells not only inhibits the proliferation and migration of RPE cells in vitro, but also suppresses the development of PVR in vivo, which indicates its therapeutic potential in treating PVR.

Keywords: P21 Waf1/Cip1 , Cell cycle arrest, Retinal pigment epithelial cells, Proliferative vitreoretinopathy

\section{Background}

Proliferative vitreoretinopathy (PVR) is characterized by the migration and proliferation of cells following a break in the retina or trauma, leading to formation of periretinal membranes, followed by contraction of cellular membranes and traction on the retina that causes retinal detachment. The retinal pigment epithelium (RPE) is a critical cell layer that undergoes proliferation in PVR. In PVR, the RPE cells

\footnotetext{
* Correspondence: phuayan2000@163.com

${ }^{\dagger}$ Equal contributors

'Department of Ophthalmology, Tianjin Medical University General Hospital, Tianjin 300052, China

Full list of author information is available at the end of the article
}

come into the vitreous and migrate to the vitreoretinal interface, where they proliferate and form traction epiretinal membranes. Effective treatment of PVR remains as a clinical challenge in ophthalmology. Although modern vitreoretinal microsurgery has obtained satisfactory results in the treatment of PVR, operational complications and/ or poor visual acuity have been associated outcomes in many cases $[1,2]$. Therefore, it is important to obtain a better understanding of the pathogenesis of this disease and to find new strategies for the prevention and treatment of PVR.

The p21 protein belongs to the family of cyclindependent kinase inhibitors (CDKIs), which play an 
important role in the regulation of cell cycle progression [3]. In cells, p21 forms quaternary complexes with cyclins, CDKs, and proliferating cell nuclear Ag, which are essential for cell cycle progression. Up-regulation of p21 expression and other CDKIs results in activation of suppression molecules of CDKs and cyclinE, allowing accumulation of hypophosphorylated $\mathrm{Rb}$ and cell cycle arrest in the G1 phase $[4,5]$. On the contrary, decreased expression of $\mathrm{p} 21$ is associated with several proliferative diseases in the eye, such as pterygium and retinoblastoma [6,7]. A previous study has shown that an increase in p21 by subconjunctival injection of the recombinant adenovirus vector-mediated p21 gene inhibits fibroproliferation and wound healing in a rabbit model of glaucoma filtration surgery [8].

Previous studies have suggested a role for p21 in tumorigenesis $[9,10]$; however, its function in PVR has not been reported. In this study, we characterized the function of p21 in the proliferation and migration of RPE cells, and explored its possible role in experimental PVR. Our findings indicated that p21 might play a protective role in PVR and may be a new target for PVR treatment.

\section{Methods \\ Reagents}

The recombinant adenovirus vector-mediated $p 21$ gene (rAd-p21) and recombinant adenovirus empty vector (rAd-NC) were obtained from GeneChem Co. Ltd. (Shanghai, China). Human RPE cells (D407 cell line) were purchased from Chuan Xiang Biological Technology Co. Ltd (Shanghai, China). Platelet rich plasma (PRP) was isolated from the peripheral blood of healthy people. The study was approved by Tianjin Medical University General Hospital Medical Ethics Committee (201315). Written informed consent for blood sampling was obtained from all participants according to the Declaration of Helsinki. After centrifuging for $10 \mathrm{~min}\left(1500 \mathrm{rpm} / \mathrm{min}\right.$ at $\left.4^{\circ} \mathrm{C}\right), 25 \mathrm{ml}$ of PRP containing platelets of $4.00 \times 10^{8} / \mathrm{ml}$ was obtained.

\section{Cell culture and recombinant adenovirus vector-mediated p21 gene transfection}

Human RPE cells (D407 cell line) were cultured in 1640 medium with $10 \%$ fetal bovine serum (FBS; Hyclone, USA), $100 \mathrm{U} / \mathrm{mL}$ penicillin, and $100 \mu \mathrm{g} / \mathrm{mL}$ streptomycin at $37^{\circ} \mathrm{C}$ in an atmosphere of $5 \% \mathrm{CO}_{2}$. Before transfection, cells were starved in serum-free medium for 24 hours. Quiescent cells were plated in six-well plates and divided into a phosphate-balanced solution (PBS) group, rAd-p21 transfection group and negative control group (rAd-NC group), and then were incubated overnight with PBS, rAdp21 and rAd-NC, respectively. After 24 hours, the cells were washed and cultured with complete medium.

\section{Cell cycle analysis by flow cytometry}

Human RPE cells $\left(1 \times 10^{6}\right)$ in six-well plates were incubated with PBS, rAd-p21 and rAd-NC transfection reagents for 24 hours. The cells were harvested and fixed in $70 \%$ ethanol. Before analysis, cells were washed with PBS and resuspended in PBS $(\mathrm{pH}=7.4)$. RNase $(100 \mu \mathrm{g} / \mathrm{ml})$ and propidium iodide $(50 \mu \mathrm{g} / \mathrm{ml})$ were added to suspend the cells for $30 \mathrm{~min}$. The use of a Becton-Dickenson FACSVantage flow cytometer system (Becton-Dickenson, USA) determined the DNA histograms, and Cell Quest software version 3.2 (Becton-Dickenson, USA) was used to analyze the cell cycle distribution. The experiments were performed in triplicate and repeated three times.

\section{Transwell assay}

Corning Transwell 3422 Chambers (Corning, USA) were used to assess human RPE cell migration in response to the $p 21$ gene. After 24 hours transfection, each group of cells (incubated with PBS, rAd-p21 or rAd-NC) was harvested and reseeded at a density of $2.5 \times 10^{4}$ per well in the upper chamber with $8 \mu \mathrm{m}$ membranes in serum-free 1640 medium. The 1640 medium containing 10\% FBS was placed in the lower chamber. After 6 hours, nonmigrating RPE cells were gently scrubbed and removed from the surface. Migrating cells attached to the membrane were fixed with $1 \%$ glutaraldehyde and stained with $0.1 \%$ crystal violet. To assess the average number of migrating cells, cells were counted in five random high power fields. All experiments were repeated three times.

\section{Western blot analysis}

The cold radio-immunoprecipitation assay (RIPA) buffer and phenylmethylsulfonyl fluoride (PMSF; a protease inhibitor) were used to prepare the cells, which were washed twice with ice-cold PBS. A cell scraper was used to gather cell lysates, which were collected and transferred to a microcentrifuge tube and centrifuged for 15 minutes at $12,000 \times \mathrm{g}\left(4^{\circ} \mathrm{C}\right)$. The supernatant was collected and a BCA protein assay kit (Pierce, Rockford, USA) was used to measure the protein content of each lysate. Electrophoresis was performed ( $25 \mathrm{ug}$ protein/well) with the use of a sodium dodecyl sulfate polyacrylamide gel electrophoresis gel, which was then transferred to a polyvinylidene difluoride membrane and analyzed by immunoblotting. The primary anti-p21 polyclonal antibody (1:200; Santa Cruz, California, USA), $\mathrm{CDK}_{2}$ polyclonal antibody (1:500; Santa Cruz, California, USA), cyclinE polyclonal antibody (1:500; Santa Cruz, California, USA) and antibody against $\beta$-actin (1:2000; Millipore, Massachusetts, USA) were used to immunodetect $\mathrm{p} 21, \mathrm{CDK}_{2}$, cyclinE and $\beta$-actin, respectively. Band densities of the $\mathrm{p} 21, \mathrm{CDK}_{2}$ and cyclinE proteins were all normalized to $\beta$-actin and quantified by ImageJ software. Western blot analyses were repeated three times. 


\section{RNA isolation and reverse transcription polymerase chain reaction}

According to the manufacturer's instructions, TRIzol reagent (Invitrogen, Carlsbad, CA) was used to isolate total RNA from the RPE. Samples of RNA (about $1 \mu \mathrm{g}$ to $2 \mu \mathrm{g}$ of total RNA) were reverse-transcribed to cDNA with gene-specific primers using the TransScript RTPCR System kit (Transgen, Beijing, China). The target gene single-stranded cDNA was amplified in a polymerase chain reaction (PCR), with sequence-specific primers of $p 21$ (forward primer: $5^{\prime}$-CCT TGT CCT TTC CCT TCA-3', reverse primer: $5^{\prime}$-TCC TTG TTC CGC TGC TAA-3', 355 bp), of CDK2 (forward primer: 5'-ATC CGC CTG GAC ACT GAG-3'; reverse primer: 5'-GTG GAG GAC CCG ATG AGA-3'; 273 bp), of cyclinE (forward primer: 5 ' -TTC CAC ACA GGA GCA AAG TAT G-3'; reverse primer: 5'-TGC AAC TTT GGA GGG TAG ATT T-3'; $377 \mathrm{bp}$ ), and of $\beta$-actin (forward primer: 5'-AGT TGC GTT ACA CCC TTT C-3'; reverse primer: 5'-CAC CTT CAC CGT TCC AGT-3', 147 bp). Expression of $\beta$-actin was used as the internal standard. Amplification was performed in a thermal cycler at $94^{\circ} \mathrm{C}$ for $30 \mathrm{~s}$, at $56^{\circ} \mathrm{C}$ for $30 \mathrm{~s}$, and at $72^{\circ} \mathrm{C}$ for $30 \mathrm{~s}$ over 35 cycles. Reverse-transcription (RT)-PCR products were electrophoresed on a $1.5 \%$ agarose gel and visualized with ethidium bromide. The intensities of the amplified cDNA fragments were estimated with a video-densitometer.

\section{Animals and induction of PVR}

Thirty adult pigmented rabbits $(2.0-2.5 \mathrm{~kg})$ were purchased from the Beijing Shahe Tongli Experimental Animal Farm (Beijing, China). All animal experiments conformed to the protocols approved by the Animal Care and Use Committee of Tianjin Medical University (TMUaMEC2013008). All of the rabbits were anesthetized with an intramuscular injection of ketamine $(50 \mathrm{mg} / \mathrm{kg}$ ) and promethazine $(25 \mathrm{mg} / \mathrm{kg})$. Before the surgery, rabbit pupils were dilated with tropicamide and the rabbits were given antibiotics. PVR was induced by intravitreal injection of $2.5 \times 10^{5}$ human RPE cells in $0.1 \mathrm{~mL}$ PRP with a 30-gauge needle. An anterior chamber paracentesis was made and approximately $0.1 \mathrm{~mL}$ aqueous humor was drained with a 30 -gauge needle before the injection.

\section{Intravitreal injection of rAd-p21}

All the rabbits were randomly divided into 3 groups randomly 7 days after PVR was induced: PBS group $(n=10$, intravitreal injection of $3 \mu \mathrm{L} \mathrm{PBS}$ ); empty vector group $(n=10$, intravitreal injection of $3 \mu \mathrm{L} \mathrm{rAd-NC);} \mathrm{and} \mathrm{gene}$ treated group $(n=10$, intravitreal injection of $3 \mu \mathrm{L} \mathrm{rAd}-$ p21). Guided by an operating microscope, rAd-p21, rAd-NC or PBS was injected into the superotemporal area posterior to the lens using a metal needle connected to a glass syringe (Hamilton Co., Reno, NV), taking care to avoid penetration of the lens or damage to the vortex veins. The injection site was $3 \mathrm{~mm}$ posterior to the superotemporal limbus. The injection site was visualized with a standard indirect ophthalmoscope and a 90-Dcondensing lens (Volk Optical Inc., Mentor, $\mathrm{OH}$ ) after each injection. The fundus status of each rabbit was acquired on days 3 , 7, 14 and 21. The findings were grouped into six stages according to Fastenberg et al. [11]; i.e., stage 0, no lesions; stage 1 , intravitreal membranes; stage 2 , retinal focal traction; stage 3, focal retinal detachment involving less than two quadrants; stage 4, extensive retinal detachment involving more than two quadrants; and stage 5 , total retinal detachment, folds, and holes. All rabbits were anesthetized and examined with a B scan to access PVR and retinal detachment, and then they were sacrificed at the end of the experiments by anesthetic overdose.

\section{Hematoxylin-eosin staining}

The eyes were enucleated and imbedded in 10\% formalin for 2 days, and then imbedded in paraffin blocks, which were then cut into $5 \mu \mathrm{m}$ thick slices and stained with hematoxylin-eosin (H\&E). The slices were photographed with a digital camera after dehydration and fixation.

\section{Western blot analysis and reverse transcription polymerase chain reaction in vivo}

The eyes were enucleated and the retinas were dissected and isolated from the RPE. The retinas were analyzed by western blot and were lysed directly on ice in $300 \mathrm{uL}$ RIPA buffer and PMSF. The lysed retinas were centrifuged and the supernatants were transferred to new tubes, and then the supernatants were processed as described previously. The RT-PCR analysis of retinas was performed as described previously.

\section{Statistics}

The data were analyzed with a one way analysis of variance and $\chi^{2}$ analysis. A value of $\mathrm{p}<0.05$ was considered to be statistically significant.

\section{Results \\ Overexpression of p21 inhibits the cell cycle in human PRE cells}

We overexpressed p21 by transfection of rAd-p21. Subsequently, to determine whether p21 inhibits the proliferation of RPE cells, we performed flow cytometry to analyze the cell cycle progression. As shown in Figure 1, rAd-p21 induced G0/G1 phase cell cycle arrest compared with the PBS and rAd-NC groups. This result suggested that upregulation of $\mathrm{p} 21$ could inhibit the proliferation of human RPE cells. 

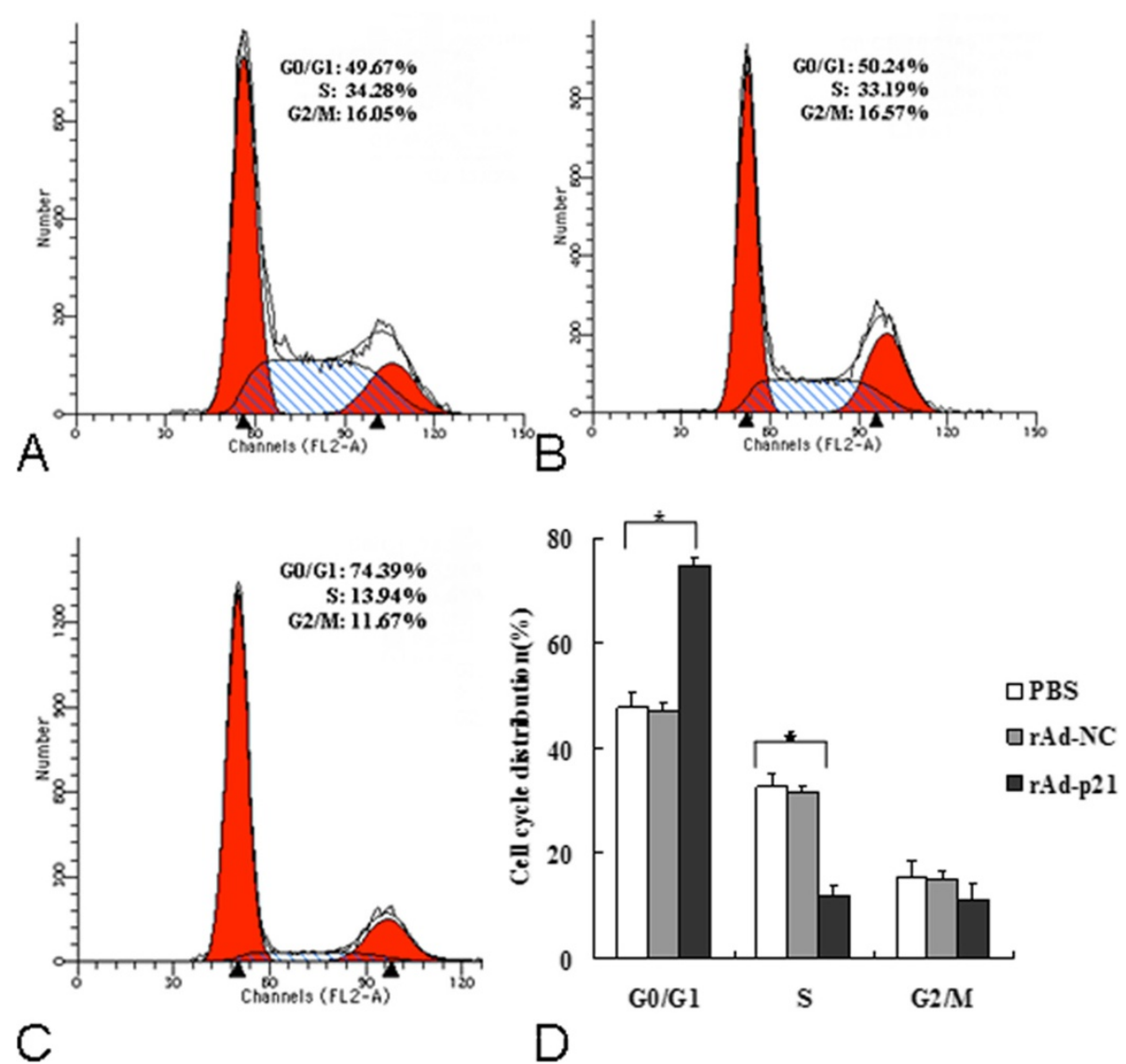

Figure 1 Effect of the $\mathbf{p} 21$ gene on the cell cycle of cultured human RPE cells. A: RPE PBS, B: RPE rAd-NC, C: RPE rAd-p21, D: Bar graph represents the quantitative data of RPE cell cycle distribution in PBS, rAd-NC and rAd-p21 groups. Each value represents the mean \pm SD of three independent experiments, each performed in triplicate $\left({ }^{*} P<0.05\right)$.

\section{Effect of the p21 gene on the migration of human RPE} cells

To examine the effect of p21 on the migration of human RPE cells, Transwell assays were performed in the PBS, rAd-NC and rAd-p21 groups. As shown in Figure 2, rAd-p21 suppressed human RPE cell migration compared with the PBS and rAd-NC groups in vitro. This result demonstrated that overexpression of p21 inhibited the migration of human RPE cells.

\section{Overexpression of p21 inhibits levels of CDK2 and CyclinE in vitro and in vivo}

To further confirm the function of p21, we transfected rAd-p21 into cultured human RPE cells, which showed that p21 expression in RPE cells was significantly increased at both protein and mRNA levels in the rAd-p21 group compared with the PBS and rAd-NC groups. Meanwhile, expression of $\mathrm{CDK}_{2}$ and cyclinE was depressed in the rAd-p21 group compared with the PBS and rAd-NC groups (Figure 3). These results suggested that overexpression of p21 suppressed the expression of $\mathrm{CDK}_{2}$ and cyclin $\mathrm{E}$ in vitro.
To investigate the potential role of the $p 21$ gene for cell cycle regulatory proteins in the inhibition of experimental PVR, we examined retinal protein and mRNA levels of p21, $\mathrm{CDK}_{2}$ and cyclinE after injecting rAd-p21 into the vitreous. Western blot and RT-PCR analysis of total retinal lysates indicated that $\mathrm{p} 21$ expression was significantly increased both at the protein and mRNA levels in the gene treated group compared with the PBS and empty vector groups, whereas expression of $\mathrm{CDK}_{2}$ and cyclinE were suppressed in the rAd-p21 treated group compared with the PBS and empty vector groups (Figure 4). The results were consistent with the experiment in vitro. This result showed that rAd-p21 could act on the retina and overexpress the protein $\mathrm{p} 21$.

\section{Effect of rAd-p21 on the inhibition of experimental PVR}

In all groups, we found that the stage of PVR progressed steadily over time by examination with indirect ophthalmoscopy. Proliferative membranes were formed without retinal detachment in the rabbit eyes in all groups on the $3^{\text {rd }}$ day after injection. There were massive proliferative membranes on the surface of the retina with focal 

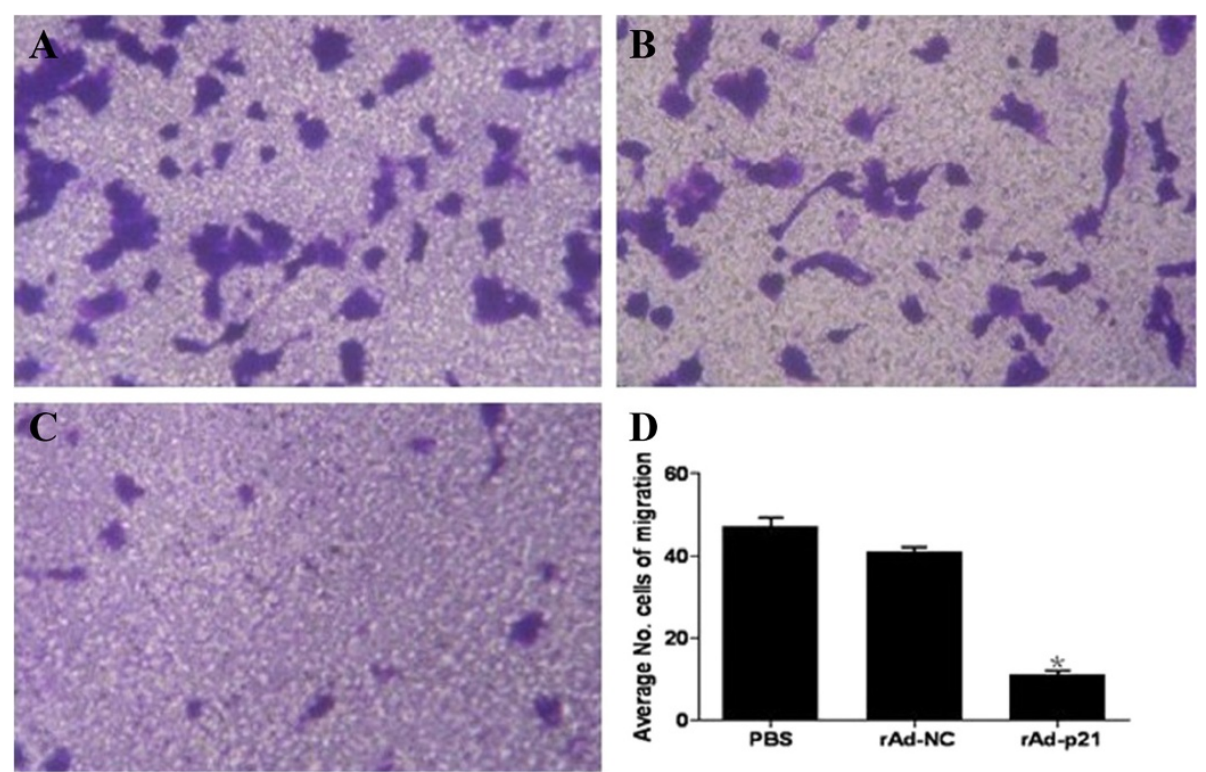

Figure 2 Effect of the $\mathbf{p} 21$ gene on the migration of cultured human RPE cells. A: RPE PBS, B RPE rAd-NC, C: RPE rAd-p21, D: Bar graphs represent the number of migrating RPE cells in PBS, rAd-NC and rAd-p21 groups. Each value represents the mean \pm SD of three independent experiments, each performed in triplicate $\left({ }^{*} \mathrm{P}<0.05\right)$.

retinal detachment in the empty vector and PBS groups on the $7^{\text {th }}$ day after injection; however, there were fewer proliferative membranes with or without retinal detachment in the gene treated group than the control groups. Then tractional retinal detachment developed in the posterior retina on the $14^{\text {th }}$ day and in the peripheral retina with total retinal detachment on the $21^{\text {st }}$ day in the control groups. However, eyes with retinal detachment in the gene treated group on the $14^{\text {th }}$ day were less prevalent than in the control group, and there was no total retinal detachment on the $21^{\text {st }}$ day. The stages of groups according to Fastenberg on the $21^{\text {st }}$ day after treatment are shown in Table 1 . The eyes in stage 4 and stage 5 were thought to have retinal detachments. The results showed that there were statistically significant differences in the rAd-p21 group compared with the other two groups on the $21^{\text {st }}$ day after treatment (Figure 5). B scans and H\&E staining of rabbit retinas on the $21^{\text {st }}$ day showed proliferative membranes with severe retinal detachment in the PBS and empty vector groups.

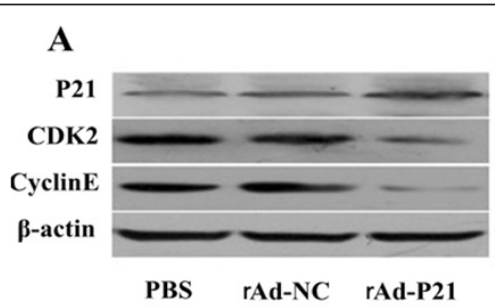

C

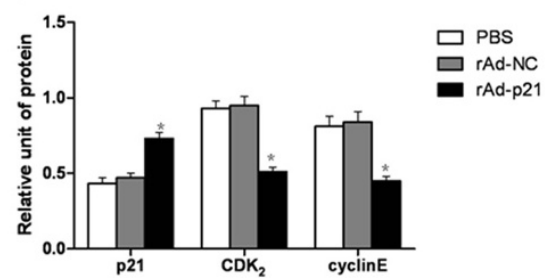

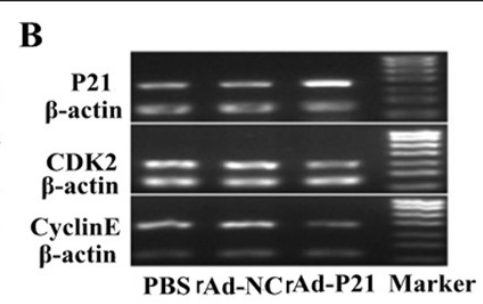

D

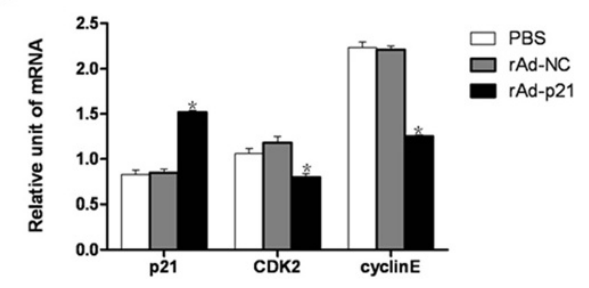

Figure 3 Protein and mRNA levels of p21, CDK2 and cyclinE in human RPE cells was examined by western blotting and RT-PCR analysis, respectively. A: Expressions of $\mathrm{P} 21, C_{2} K_{2}$ and cyclinE were assessed by western blot analysis in PBS, rAd-NC and rAd-p21 groups. $\beta$-Actin was used as the control. B: Expression of p21, CDK 2 and cyclinE mRNA were assessed by RT-PCR analysis. C, D: Quantitative analysis of proteins and mRNA by densitometric scan. $(n=6)$. The error bars represent the standard deviation. There were statistically significant differences in $p 21, C_{2}$ and cyclinE protein and mRNA levels in the rAd-p21 group compared with the other two groups. $\left({ }^{*} p<0.05\right)$. 


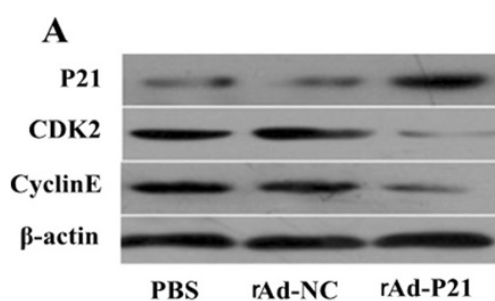

C

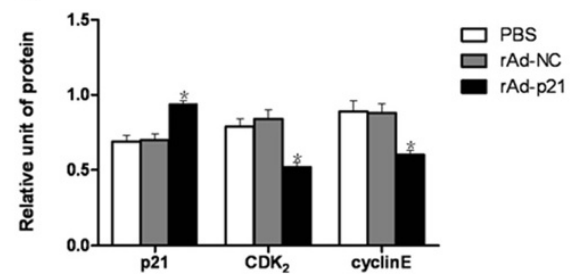
$-21 \mathrm{KDa}$
$-33 \mathrm{KDa}$
$-42 \mathrm{KDa}$
$-50 \mathrm{KDa}$
B 0KDa $\begin{array}{r}\text { CyclinE } \\ \beta \text {-actin }\end{array}$

D

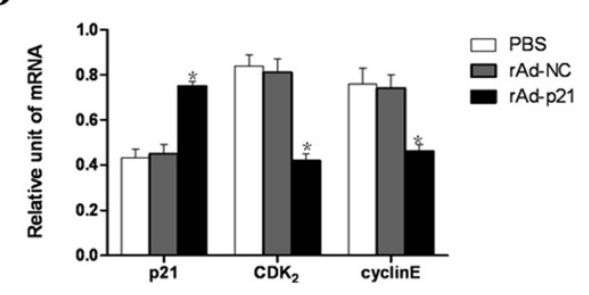

Figure 4 Retinal expression of p21, CDK2 and cyclinE protein and mRNA levels after treatment analyzed by western blotting and RT-PCR assays, respectively. A: Expression of P21, CDK 2 and cyclinE were assessed by western blot analysis in PBS, rAd-NC and rAd-p21 groups in vivo. B: Expressions of p21, CDK 2 and CyclinE mRNA were assessed by RT-PCR analysis in the three groups in vivo. C, D: Quantitative analysis of proteins and mRNA by densitometric scans $(n=6)$. The columns are the mean \pm SD of three independent groups. There were statistically significant differences in p21, CDK 2 and cyclinE protein and mRNA levels in the p21 gene treated group in vivo compared with the other two groups $\left({ }^{*} p<0.05\right)$.

However, intravitreal injection of rAd-p21 inhibited proliferative membranes without severe retinal detachment. This result indicated that overexpression of p21 inhibited PVR progression (Figure 6).

\section{Discussion}

PVR is a vision-threatening disease and a common complication after surgery to correct rhegmatogenous retinal detachment. PVR is a proliferative response within the eye. Its pathological processes include inflammatory cell infiltration, proliferation of cell growth and the formation of scars. Other studies have demonstrated that fibrocellular membranes in PVR mainly consist of RPE cells, macrophages, glial cells, periostin and fibroblastlike cells $[12,13]$. Injection of those cells into the vitreous in animal models, whether they are macrophages, fibroblasts or RPE cells, results in pathology that mimics PVR $[14,15]$. During the course of PVR formation, the proliferation and migration of RPE cells is a very important step. RPE cells move from under the photoreceptor layer into the vitreous cavity and stay on the

Table 1 Stages of groups according to Fastenberg on the 21 st day after treatment

\begin{tabular}{cccc}
\hline Stage & PBS group & rAd-NC group & rAd-p21 group \\
\hline 0 & 0 & 0 & 0 \\
1 & 0 & 0 & 1 \\
2 & 0 & 0 & 1 \\
3 & 1 & 1 & 5 \\
4 & 4 & 3 & 3 \\
5 & 5 & 6 & 0 \\
\hline
\end{tabular}

retinal surface to form an epiretinal membrane. However, some studies have already shown that RPE cells are very poor inducers of PVR alone when injected in a rabbit eye. Therefore, we chose to use RPE cells in an in vitro experiment and RPE cells and PRP to induce PVR in an animal model.

P21 is known as an important CDKI with a wide range of kinase inhibition activity, which can effectively inhibit $\mathrm{CDK}_{2}$ and cyclins to prevent cells from going through the $\mathrm{G} 1 / \mathrm{S}$ phase checkpoint, and to inhibit cell proliferation $[16,17]$. Previous studies have shown that p21 suppressed tumor cell migration and proliferation $[9,10]$. PVR

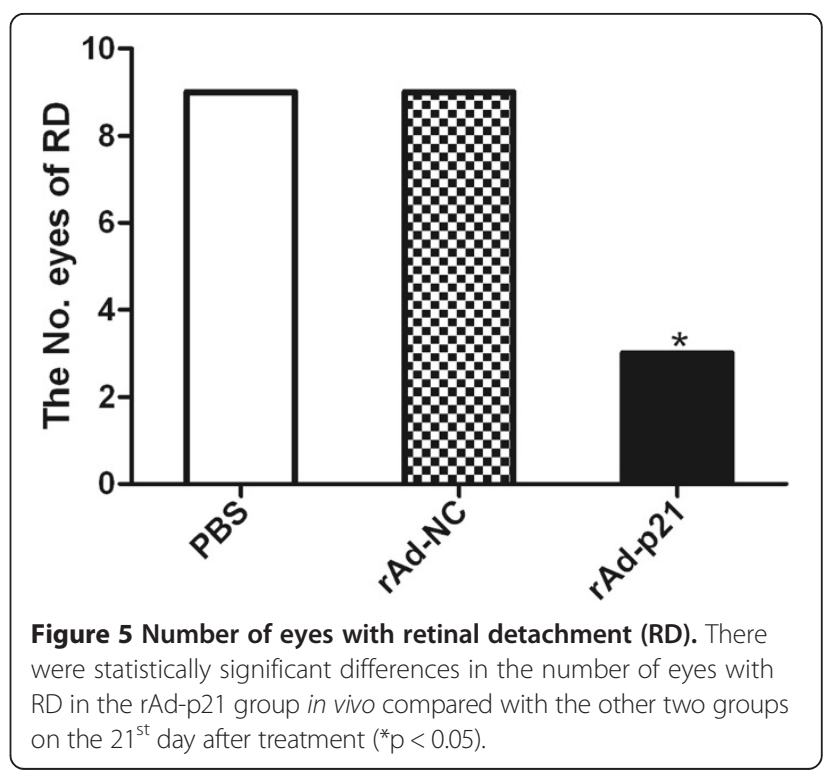



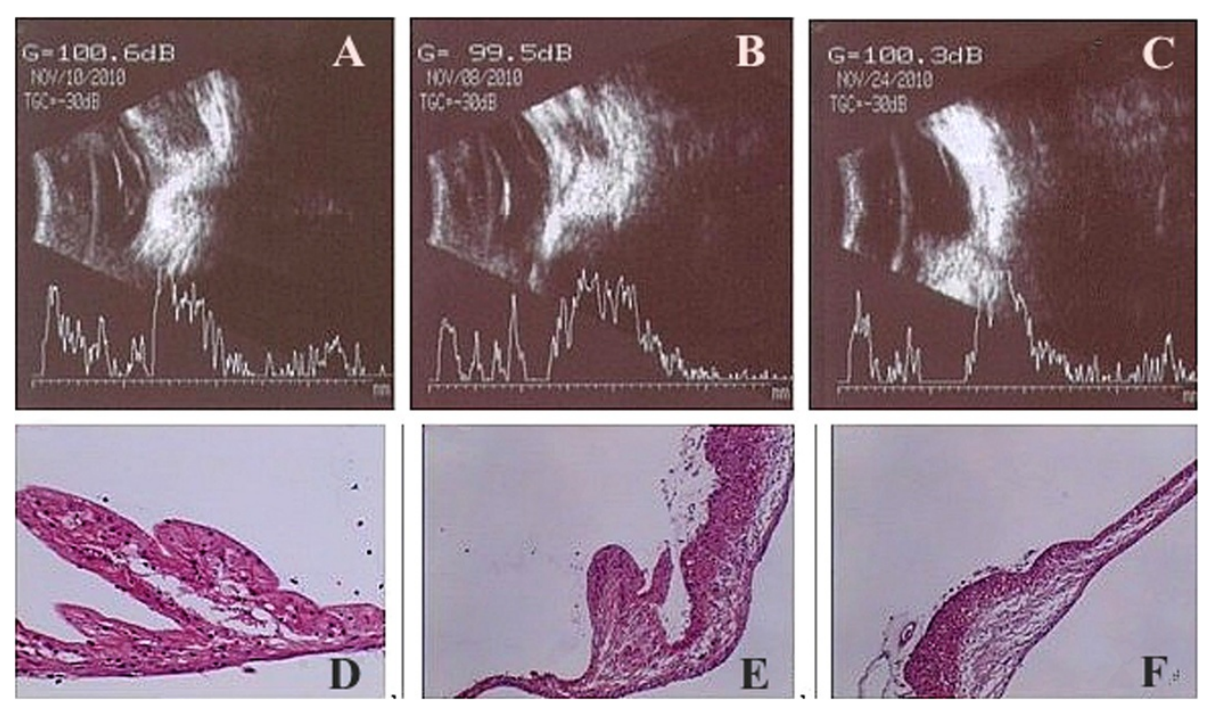

Figure $\mathbf{6}$ B scans and H\&E staining (B scan, A-C; H\&E staining, D-F, 200X). The retinas of rabbits at 21 days after treatment revealed that rAd-p21 significantly inhibited PVR. B scans showed significantly proliferative membranes with severe retinal detachment in the PBS and $r$ Ad-NC groups $(\mathbf{A}, \mathbf{B})$. However, rAd-p21 treatment inhibited proliferative membranes without severe retinal detachment. (C) H\&E staining indicated that retinal microanatomy had more integrity in the rAd-p21 group (F) than in groups PBS and rAd-NC (D,E).

has many parallels to cancer. Antiproliferative and cell cycle blocking agents are commonly used in the treatment of PVR $[18,19]$. Furthermore, p21 showed low expression levels in PRE-19 cells delivered from human RPE cells, which are important in the pathogenesis of PVR [20]. However, there have been no reports of p21 gene therapy in PVR. Finally, our study indicated that p21 has a role in the suppression of PRE cell proliferation and migration in vitro, and inhibits PVR in vivo.

Adenovirus-mediated gene transfection technology has been widely applied in research on ophthalmic diseases [21-23]. For example, clinical trials have indicated that adenovirus vectors containing wild type p53 was a safe, feasible gene-therapy approach [24]. In our study, p21 was successfully transfected into the human D407 RPE cell line by an adenovirus vector in vitro, and the protein and gene of $\mathrm{p} 21$ showed significantly higher expression in the rAd-p21 group compared with the rAd-NC group.

Up-regulation of p21 arrested the cell cycle at the G1 phase, and the number of cells in the G0 and G1 phases was significantly increased. P21 belongs to the Cip/Kip family, which is one of the CDKIs, and can block the activity of cyclin/CDK complexes, specifically $\mathrm{CDK}_{2}$ in E/ACDK2 cyclin complexes [3]. These complexes block the cell-cycle transition from the G1 phase to the $\mathrm{S}$ phase. P21 is regulated by two different pathways, i.e., a p53dependent pathway (DNA damage leading to the activation of p53 and upregulation of p21 causing cell cycle blockage in the G1 phase with possible DNA repair or induction of apoptosis), and a p53-independent pathway (through cell growth factors, such as interferon- $\beta$ and tumor necrosis factor- $\alpha$, which are able to induce p21 in p53-deficient cells in quiescence) [25,26]. Our results also indicated that p21 overexpression was connected with the depression of $\mathrm{CDK}_{2}$ and cyclinE in human RPE cells, leading to arrest of the cell cycle and reduction of the proliferation of cells.

Cell migration is another important process in the development of PVR. Without migration, RPE cells would not be involved in the formation of a proliferative epiretinal membrane by entering the vitreous cavity and settling down on the surface of the retina. In this study, p21 overexpression inhibited the migration of RPE cells, which is consistent with its effects on the migration of vascular smooth muscle cells (SMCs), epithelial cells and cancer cells [27-30]. Previous studies have reported that the migration of RPE cells depended on the PI3K/AKT and MAPK signaling pathways, and p21 inducing cell cycle progression and survival also depended on PI3K/ AKT and MAPK activations [31-33]. Therefore, the potential mechanism of p21 depressing RPE cell migration probably depends on PI3K/AKT and MAPK signaling pathways. The results will be verified by further experiments.

Experimental models of PVR were conducted to investigate intraocular proliferation. Intraocular injection of RPE cells and PRP to establish a PVR animal model is one of the commonly used methods that can induce intravitreal proliferative responses. The response will reach a peak for nearly 2 weeks and develop tractional retinal detachment at 3-4 weeks after injection [34]. Furthermore, we have previously shown that the expression of p21 decreased gradually from 7 days and reached the lowest point at 2 weeks after PVR induction. The expression of p21 and PVR development has a negative correlation. In agreement 
with previous studies, we administered rAd-p21 by intravitreal injection 7 days after PVR induction. Increased mRNA and protein expression of p21 in vivo by western blotting and RT-PCR indicated that rAd-p21 could incorporate within the retina. The development of a proliferative membrane and retinal detachment, shown by $\mathrm{B}$ scans and HE staining, in the gene treated group was lighter than in the control groups. Western blot and RTPCR showed that the expression of p21 was up-regulated, whereas the expression of $\mathrm{CDK}_{2}$ and cyclinE were downregulated after treatment. These results were consistent with the results in vitro. Our study indicated that treatment with p21 not only inhibited human RPE cell proliferation and migration in vitro but also probably arrested the RPE cells in the G1 phase by regulating $\mathrm{CDK}_{2}$ and cyclinE activity to inhibit the formation of proliferative membranes and slowed down PVR development procession in the rabbit PVR model. The signal pathway of p21 inhibited PVR is still not clear. Previous studies reported that the regulation of $\mathrm{p} 21$ was controlled at the transcriptional level by both p53 dependent and independent mechanisms [35]. The relationship between p21 and p53 was mainly studied in tumors, and is perhaps similar in PVR.

During the treatment in vivo, all rabbits tolerated the treatment well and there was no increase in systemic toxicity. In addition, there was no cataract, glaucoma, or endophthalmitis found by slit lamp and indirect ophthalmoscopy during the treatment.

As is known, although RPE cells are main cells that participate in epiretinal membrane formation, macrophages and fibroblasts also play key roles in this progression. Further research is necessary to determine whether increased expression of p21 suppresses PVR in those cells.

\section{Conclusions}

Our results suggested a role for the p21 gene in the inhibition of the proliferation and migration of PRE cells in vitro, and showed the $p 21$ gene can reduce the occurrence of severe PVR cases through inhibition the expression of $\mathrm{CDK}_{2}$ and cyclin E. P21 gene may be a new therapeutic target for PVR.

\section{Competing interests}

The authors state that they have no significant financial interest or other relationship with any product manufacturer or provider of services discussed in this article. The authors do not discuss the use of off-label products, which include unlabeled, unapproved, or noninvestigative products or devices.

\section{Authors' contributions}

YW and ZY carried out the molecular genetic studies, western blotting and $P C R$, and participated in drafting the manuscript. $C Y$ participated in the design of the study and edited the article. JH established the animal model and carried out the B scan, western blotting and PCR. HL carried the histology. ZZ performed the statistical analysis and provided technical help. HY conceived of the study and participated in the design of the study. All authors read and approved the final manuscript.

\section{Acknowledgment}

This work was supported by Natural Science Foundation of Tianjin grant $12 J$ CYBJC33900.

\section{Author details}

'Department of Ophthalmology, Tianjin Medical University General Hospital, Tianjin 300052, China. ${ }^{2}$ Shanxi Eye Hospital, Taiyuan City, Shanxi Province 030002, China

Received: 13 July 2014 Accepted: 14 November 2014

Published: 25 November 2014

\section{References}

1. Sadaka A, Giuliari GP: Proliferative vitreoretinopathy: current and emerging treatments. Clin ophtalmol 2012, 6:1325-1333.

2. Cunningham MA, Tarantola RM, Folk JC, Sohn EH, Boldt HC, Graff JA, Elkins K, Russell SR, Mahajan VB: Proliferative vitreoretinopathy may be a risk factor in combined macular hole retinal detachment cases. Retina 2013, 33:579-585

3. Fillies T, Woltering M, Brandt B, Van Diest JP, Werkmeister R, Joos U, Buerger $\mathrm{H}$ : Cell cycle regulating proteins p21 and p27 in prognosis of oral squamous cell carcinomas. Oncol Rep 2007, 17:355-359.

4. Fischer PM, Gianella-Borradori A: CDK inhibitors in clinical development for the treatment of cancer. Expert Opin Investig Drugs 2003, 12:955-970

5. Harper JW, Elledge SJ, Keyomarsi K, Dynlacht B, Tsai LH, Zhang P. Dobrowolski S, Bai C, Connell-Crowley L, Swindell E: Inhibition of cyclin-dependent kinases by p21. Mol Biol Cell 1995, 6:387-400.

6. Ueda Y, Kanazawa S, Kitaoka T, Dake Y, Ohira A, Ouertani AM, Amemiya T: Immunohistochemical study of p53, p21 and PCNA in pterygium. Acta Histochem 2001, 103:159-165.

7. Audo I, Darjatmoko SR, Schlamp CL, Lokken JM, Lindstrom MJ, Albert DM, Nickells RW: Vitamin D analogues increase p53, p21, and apoptosis in a xenograft model of human retinoblastoma. Invest Ophthalmol Vis Sci 2003, 44:4192-4199.

8. Heatley G, Kiland J, Faha B, Seeman J, Schlamp CL, Dawson DG, Gleiser J, Maneval D, Kaufman PL, Nickells RW: Gene therapy using p21WAF-1/Cip-1 to modulate wound healing after glaucoma trabeculectomy surgery in a primate model of ocular hypertension. Gene Ther 2004, 11:949-955.

9. Weiss RH: P21Waf1/Cip1 as a therapeutic target in breast and other cancers. Cancer Cell 2003, 4:425-429.

10. Zhao YF, Wang CR, Wu YM, Ma SL, Ji Y, Lu YJ: P21 (waf1/cip1) is required for non-small cell lung cancer sensitive to Gefitinib treatment. Biomed Pharmacother 2011, 65:151-156.

11. Fastenberg DM, Diddie KR, Dorey K, Ryan SJ: The role of cellular proliferation in an experimental model of massive periretinal proliferation. Am J Ophthalmol 1982, 93:565-572.

12. Chiquet C, Rouberol F: Proliferative vitreoretinopathy: pathophysiology and clinical diagnosis. J Fr Ophtalmol 2014, Epub ahead of print.

13. Ishikawa K1, Yoshida S, Nakao S, Nakama T, Kita T, Asato R, Sassa Y, Arita R, Miyazaki M, Enaida H, Oshima Y, Murakami N, Niiro H, Ono J, Matsuda A, Goto Y, Akashi K, Izuhara K, Kudo A, Kono T, Hafezi-Moghadam A, Ishibashi T: Periostin promotes the generation of fibrous membranes in proliferative vitreoretinopathy. FASEB J 2014, 28:131-142.

14. Lin ML, Li YP, Li ZR, Lin JX, Zhou XL, Liang D: Macrophages acquire fibroblast characteristics in a rat model of proliferative vitreoretinopathy. Ophthamic Res 2011, 45:180-190.

15. Ganti R, Hunt RC, Parapuram SK, Hunt DM: Vitreous modulation of gene expression in low-passage human retinal pigment epithelial cells. Invest Ophthalmol Vis Sic 2007, 48:1853-1863.

16. Neganova I, Zhang X, Atkinson S, Lako M: Expression and functional analysis of $\mathrm{G} 1$ to $\mathrm{S}$ regulatory components reveals an important role for CDK2 in cell cycle regulation in human embryonic stem cells. Oncogene 2009, 28:20-30.

17. Cazzalini O, Scovassi Al, Savio M, Stivala LA, Prosperi E: Multiple roles of the cell cycle inhibitor p21(CDKN1A) in the DNA damage response. Mutat Res 2010, 704:12-20.

18. Velikay M, Stolba U, Wedrich A, Datlinger P, Binder S, Handl-Zeller L: Irradiation pretreatment before fibroblast implantation in experimental PVR. Int Opthalmol 1993, 17:191-193. 
19. Binder S, Bonnet M, Velikay M, Gerard JP, Stolba U, Wedrich A, Hohenberg $\mathrm{H}$ : Radiation therapy in proliferative vitreoretinopathy. A prospective randomized study. Graefes Arch Clin Exp Opthalmol 1994, 232:211-214.

20. Nair AR, Schliekelman M, Thomas MB, Wakefield J, Jurgensen S, Ramabhadran R: Inhibition of p53 by lentiviral mediated shRNA abrogates $\mathrm{G} 1$ arrest and apoptosis in retinal pigmented epithelial cell line. Cell Cycle 2005, 4:697-703.

21. Cashman SM, Ramo K, Kumar-Singh R: A non membrane-targeted human soluble CD59 attenuates choroidal neovascularization in a model of age related macular degeneration. PLoS One 2011, 6:19078.

22. Han J, Yuan Z, Yan H: Inhibitory effect of adenoviral vector-mediated delivery of p21WAF1/CIP1 on retinal vascular endothelial cell proliferation and tube formation in cultured Rhesus monkey cells (RF/6A). Curr Eye Res 2013, 38:670-673.

23. Meng F, Wang $X$, Gu P, Wang Z, Guo W: Induction of retinal ganglion-like cells from fibroblasts by adenoviral gene delivery. Neuroscience 2013, 250:381-393.

24. Zhang S, Li Y, Li L, Zhang Y, Gao N, Zhang Z, Zhao H: Phase I study of repeated intraepithelial delivery of adenoviral p53 in patients with dysplastic oral leukoplakia. J Oral Maxillofac Surg 2009, 67:1074-1082.

25. Ryazantseva NV, Novitskii W, Zhukova OB, Biktasova AK, Chechina OE, Sazonova EV, Radzivil TT, Wice AN, Chasovskikh NY: Role of NF-kB, p53, and p21 in the regulation of TNF-a mediated apoptosis of lymphocytes. Bull Exp Biol Med 2010, 149:50-53.

26. Lee JH, Lee SY, Lee JH, Lee SH: P21 WAF1 is involved in interferon- $\beta$-induced attenuation of telomerase activity and human telomerase reverse transcriptase (hTERT) expression in ovarian cancer. Mol Cells 2010, 30:327-333.

27. Stotz WH, Li D, Johns RA: Exogenous nitric oxide upregulates p21(waf1/cip1) in pulmonary microvascular smooth muscle cells. J Vasc Res 2004, 41:211-219.

28. Stehr W, Mercer TI, Bernal NP, Erwin CR, Warner BW: Opposing roles for p21(waf1/cip1) and p27(kip1) in enterocyte differentiation, proliferation, and migration. Surgery 2005, 138:187-194.

29. Chatzistamou I, Dioufa N, Trimis G, Sklavounou A, Kittas C, Kiaris H, Papavassiliou AG: P21/waf1 and smooth-muscle actin alpha expression in stromal fibroblasts of oral cancers. Cell Oncol 2011, 34:483-488.

30. Wang JJ, Hung HF, Huang ML, Lee HJ, Chern YT, Chang YF, Chi CW, Hsu YC: Role of p21 as a determinant of 1,6-Bis[4-(4-amino-3-hydroxyphenoxy) phenyl] diamantane response in human HCT-116 colon carcinoma cells. Oncol Rep 2012, 27:529-534.

31. Chan CM, Chang HH, Wang VC, Huang CL, Hung CF: Inhibitory effects of resveratrol on PDGF-BB-induced retinal pigment epithelial cell migration via PDGFR $\beta$, PI3K/Akt and MAPK pathways. Plos One 2013, 8:56819.

32. Zhang L, Wang F, Jiang Y, Xu S, Lu F, Wang W, Sun X, Sun X: Migration of retinal pigment epithelial cells is EGFR/PI3K/AKT dependent. Front BiosC 2013, 1:661-671.

33. Pérez-Tenorio G, Berglund F, Esquerra Merca A, Nordenskjöld B, Rutqvist LE, Skoog L, Stål O: Cytoplasmic p21WAF1/CIP1 correlates with Akt activation and poor response to tamoxifen in breast cancer. Int J Oncol 2006, 28:1031-1042

34. Agrawal RN, He S, Spee C, Cui JZ, Ryan SJ, Hinton DR: In vivo models of proliferative vitreoretinopathy. Nat Protoc 2007, 2:67-77.

35. Liu S, Bishop WR, Liu M: Differential effectsof cellcycle regulatory protein p21(WAF1/Cip1) on apoptosis and sensitivity to cancer chemotherapy. Drug Resist Updat 2003, 6:183-195.

doi:10.1186/1471-2415-14-144

Cite this article as: Wang et al:: Overexpression p21WAF1/CIP1 in suppressing retinal pigment epithelial cells and progression of proliferative vitreoretinopathy via inhibition CDK2 and cyclin E. BMC Ophthalmology 2014 14:144.

\section{Submit your next manuscript to BioMed Central and take full advantage of:}

- Convenient online submission

- Thorough peer review

- No space constraints or color figure charges

- Immediate publication on acceptance

- Inclusion in PubMed, CAS, Scopus and Google Scholar

- Research which is freely available for redistribution

Submit your manuscript at www.biomedcentral.com/submit
C BioMed Central 